Citation: Lerdo-Morales, H., A., Chávez-Valdez, R. E., Figueroa-Millán, P., E., Benavides-Delgado, J. \& R., \& Bricio-Barrios E. E. (2021). Web-based system for the traceability of cultivated Nile Tilapia based on ISO 12877: 2011 Agro Productividad. https://doi. org/10.32854/agrop.v14i8.1937

Editor in Chief: Dr. Jorge Cadena Iñiguez

Received: January, 2021.

Accepted: July, 2021.

Estimated publication date: September, 2021

This work is licensed under a Creative Commons Attribution-NonCommercial 4.0 International license.

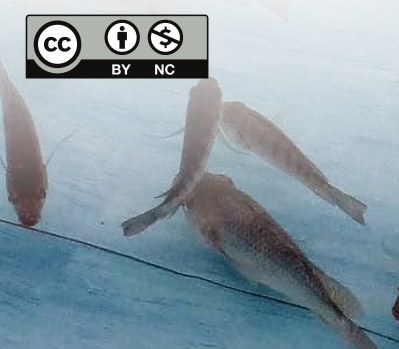

\section{Web-based system for the traceability of cultivated Nile Tilapia based on ISO 12877: 2011}

\author{
Lerdo-Morales Hember Aldair ${ }^{1 *}$ iD, Ghávez-Valdez Ramona Evelia ${ }^{1}$ iD, \\ Figueroa-Millán Patricia Elizabeth $^{1}$ iD, Benavides-Delgado J. Reyes ${ }^{1}$ iD, \\ Bricio-Barrios Elena Elsa ${ }^{1}$ iD \\ 1 Tecnológico Nacional de México/IT Colima. Av. Tecnológico No. 1. Colonia Liberación. Villa de Álvarez, \\ Colima, México. CP. 28976. \\ * Correspondence author: halm1856@hotmail.com
}

\begin{abstract}
Objective: To describe the systematization of the Nile tilapia cultivation process using a computer system for production and marketing traceability based on ISO 12877:2011 standard and web technologies.

Design/methodology/approach: A documentary and field investigation were conducted to learn about the Nile tilapia production process currently applied; traceability was evaluated based on Double T and María del Carmen study cases, aquaculture farms located in the municipalities of Manzanillo and Armería located in the state of Colima, México; the process was contrasted with the ISO standard and the system was developed and implemented.

Results: A Traceability System that records backward, internal, and forward procedural activities in the cultivation and marketing of tilapia. The system improves food safety control by registering lot care based on the ISO standard, resulting in well-defined traceable processes in the production and commercialization of the Nilotic tilapia.

Limitations on study/implications: The results shown are related to the development and implementation of the system; however future work is yet to be carried out to assess its effect on the production and commercialization of farmed tilapia, as well as the efficiency of traceability.

Findings/conclusions: The system was developed taking into consideration the necessary indicators for an ISO certification. Hence, aside from simplifying the registration and consultation of information, the producing company has the benefit of earning a certification for the aquaculture production process, creating additional value to its products.
\end{abstract}

Keywords: Food safety, Web system, Tilapia, Traceability.

\section{INTRODUCTION}

Nile tilapia (Oreochromis niloticus) was the fifth most produced species worldwide in 2017, representing more than four million tons, due to its high consumer acceptance and its nutritional value (FAO, 2017). In the same year, Tilapia imports in México were the highest compared to other species, with only more than one million tons (CONAPESCA, 2017), making evident a strong competition for national producers. However, issues such as the poor application of technology in production processes and the unfavorable climatic 
conditions that prevail in many states of the Mexican Republic have harmed national production (Pea et al., 2016). Despite this, in the past decade, national aquaculture production grew slightly over 2\% (CONAPESCA 2010; CONAPESCA 2018).

On the other hand, even with government programs such as those of SENASICA aimed at food safety, it is essential to trace food products through the traceability chain and raising awareness among producers about safe food production (Chávez et al., 2019), giving them a competitive advantage and being one of several mandatory conditions for those who wish to export their products to new markets (Huerta and Sandoval, 2018); In addition, it promotes the growth of national aquaculture output, the advantages of producers and the decrease of imports, as well as the enhancement of food quality and safety in Mexico (Herrera et al., 2013). Despite this, the latter are compromised by the communication complexity between those involved in the supply chain, and how weak each link in the supply chain may be (Yu, 2020). Consequently, it is necessary to integrate information systems that allows more effective data organization, storage, and analysis, thereby improving confidence and transparency in food products (Nikolaus, 2020). For this purpose, food traceability systems were created and thus, scientific publications related to traceability have increased by 41 percent annually over the last two decades, demonstrating how producers in various countries around the world have incorporated technology into the supervision of cultivation processes (Callejas and Alvarez, 2020).

ValorMar R\&D, a fisheries and aquaculture value chain traceability platform from Portugal, integrates business processes to identify the required data to be collected and processed centrally (Rosado, 2019). The food traceability system in Jiangsu, China, incorporates a count of expired and recycled food, to predict food safety issues (Cao, 2017). In Panama, a digital platform model based on blockchain is proposed to optimize agricultural supply chain processes by establishing smart contracts enabling the creation of an online market between costumers and producers, removing the need for intermediaries (Caballero and Rivera, 2019). In Sonora, Mexico, SITAGAN, a software developed for cattle producers, is used to maintain a punctual record of production history such as breed, day of birth, birth weight, among others (Valdez et al., 2011). On the other hand, new technological solutions have been created, such as traceability systems based on video monitoring (Mao, 2015), as well as the use of RFID technologies for effective data input, protecting their veracity (Zhao, 2014). However, most of these solutions lack standards, generating diverse outcomes, limiting efficient and transparent information flow in supply chains, hence the importance of a system based on international standards (Šenk et al., 2013).

\section{MATERIALS AND METHODS}

In this applied research, a web system was designed based on the international standard ISO 12877:2011 for the traceability of Nile tilapia farms in the state of Colima, México, and implemented with open-source technologies, using the Double T farm and the Maria del Carmen farm as case studies; the first is in Armeria and the second in Manzanillo, both municipalities of Colima. 
The literature review showed the need to adopt a standardized norm. ISO 12877:2011 of the ISO Technical Committee ISO / TC 234, Fisheries and aquaculture (ISO, 2011) was recognized as the current instrument to monitor and trace tilapia production. It applies to the following food industry operators: fish feed production; breeding, hatcheries; fish farms; live fish transporters; processors; transporters and stockists; traders and wholesalers; retailers and caterers. Therefore, the traceability information system presented focuses on the operators: Breeding, which generates fish eggs from broodstock as the final product; Hatcheries, which receive fish eggs and maintain them during the hatching stage and beginning of the artificial feeding stage, increasing their size and weight, until they are considered fry; Fish farms, which accept the fry and keep them throughout the growth stage until they reach commercial sizes, to facilitate sale to the customer or company involved in processing the fish for different reasons; and Live fish transporters who transport fry or juvenile tilapia. They are required to identify themselves fiscally, register the location of their establishments, keep records of inputs, partners, suppliers, commercial units received and shipped, identify and register the diseases that have occurred in tilapia production and the treatments applied to cure them, all of this for the benefit of food quality and safety.

In addition, a field investigation was carried out using the farms listed in abstract section as a case study, and a semi-structured interview was used to determine which of the ISO standards' requirements are met on these farms. Table 1 lists the most relevant indicators proposed in the ISO standard, indicating with a $\checkmark$ those already considered by the producers and with an $\times$ those that were not.

Subsequently, the main needs in the production processes were identified and matched with the indicators of the ISO standard, specifically for tilapia breeding and fattening, highlighting the accuracy of the data, the increase in the frequency of records related to batches produced, physical-chemical parameters, inputs, customers, personnel, and suppliers, which help to monitor the behavior of production and improve the organization of the farms in terms of attention to the production process.

Table 1. Indicators evaluated in the interview.

\begin{tabular}{l|c|c}
\multicolumn{1}{c|}{ Indicator } & $\begin{array}{c}\text { María del } \\
\text { Carmen Farm }\end{array}$ & $\begin{array}{c}\text { DobleT } \\
\text { Farm }\end{array}$ \\
\hline Identification and registration of the commercial lot & $\checkmark$ & $\checkmark$ \\
\hline Species record for each commercial lot & $\checkmark$ & $\checkmark$ \\
\hline Record of the average temperature per day & $\checkmark$ & $\checkmark$ \\
\hline Record of the starvation period. & $\times$ & $\times$ \\
\hline Record of the tank where the batch was kept & $\checkmark$ & $\checkmark$ \\
\hline Record of oxygen & $\checkmark$ & $\checkmark$ \\
\hline Record of diseases presented & $\times$ & $\times$ \\
\hline Record of treatment used for the diseases presented & $\times$ & $\times$ \\
\hline Record of feeding & $\checkmark$ & $\checkmark$ \\
\hline Record of batch delivery to other businesses & $\times$ & $\times$ \\
\hline Record of reception of batches with their respective technical data sheet & $\times$ & $\times$ \\
\hline
\end{tabular}


Considering all of the foregoing, the conceptual model of the traceability system was developed in line with the criteria of the ISO standard stated above, which is shown in (Figure 1).

As can be seen in Figure 1, the conceptual model considers two actors: the administrator who oversees enabling and validating production-related activities; and the general user (employee), in responsibility of documenting specific production activities. It consists of three modules: backward, internal, and forward traceability; it maintains the records according to the ISO 12877:2011 standard in a centralized database, having a connection to databases of alternate projects that are responsible for automating the recording of physicochemical and feed parameters.

\section{RESULTS AND DISCUSSION}

The development of the web system for tilapia traceability, based on documentary and field research, made it possible to achieve the objective of systematizing tilapia farming through the implementation of a computerized system that allows identifying the traceability of tilapia farming according to the operators established by ISO 12877: 2011 as Breeding, Hatcheries, Fish farms and Transport of live fish; and the traceable elements (commercial unit and shipped unit) are accessible via technical sheets automatically generated by the system, in which there is the option to download a $\mathrm{QR}$ code containing the same information, to simplify information management, as illustrated in (Figure 2) and (Figure 3).

As can be seen, Figure 2 shows the description of the unit shipped, i.e., the name of the sending and receiving producer, as well as the date shipped, quantity shipped, species and its unique logistic identifier.

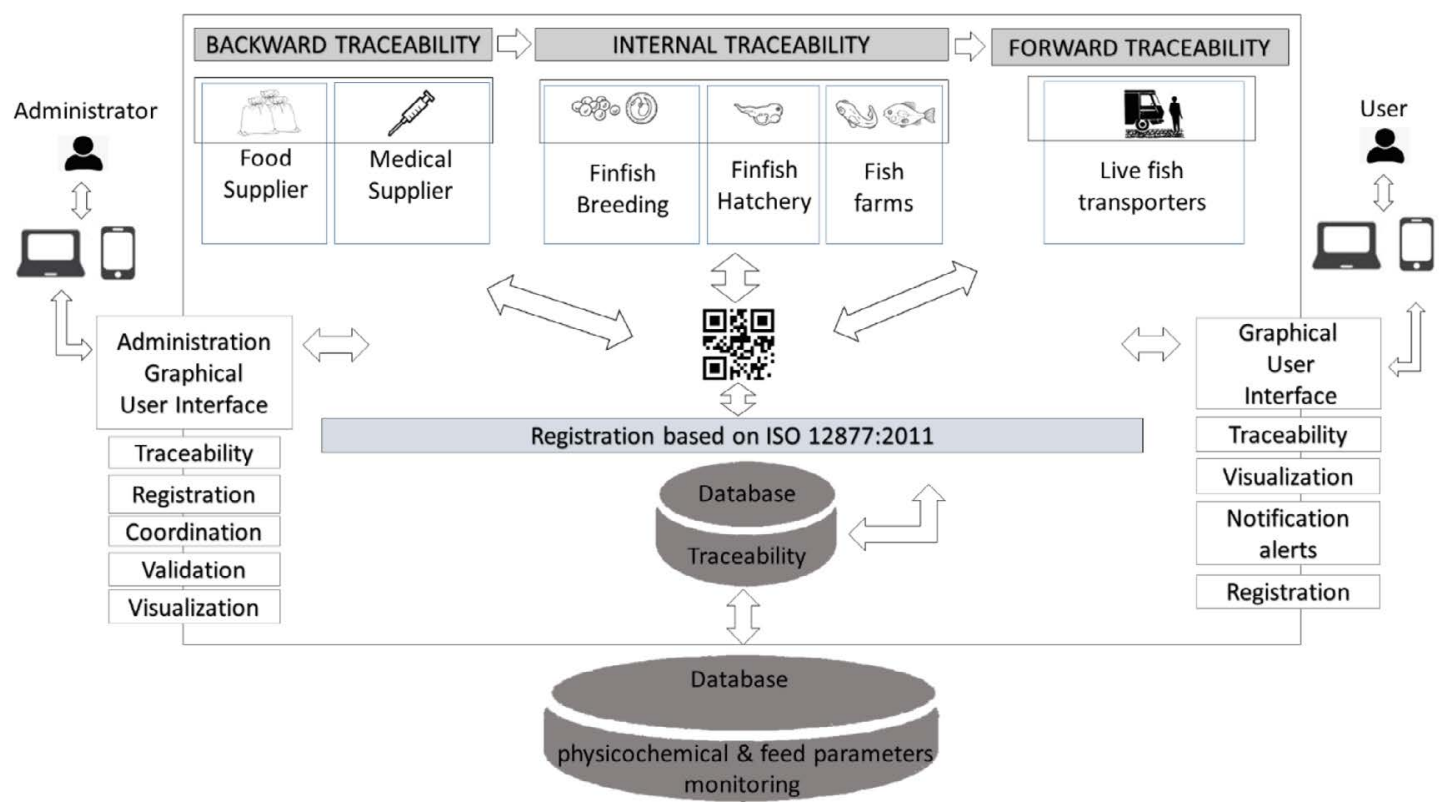

Figure 1. Conceptual Model of the Tilapia Traceability Web System. 


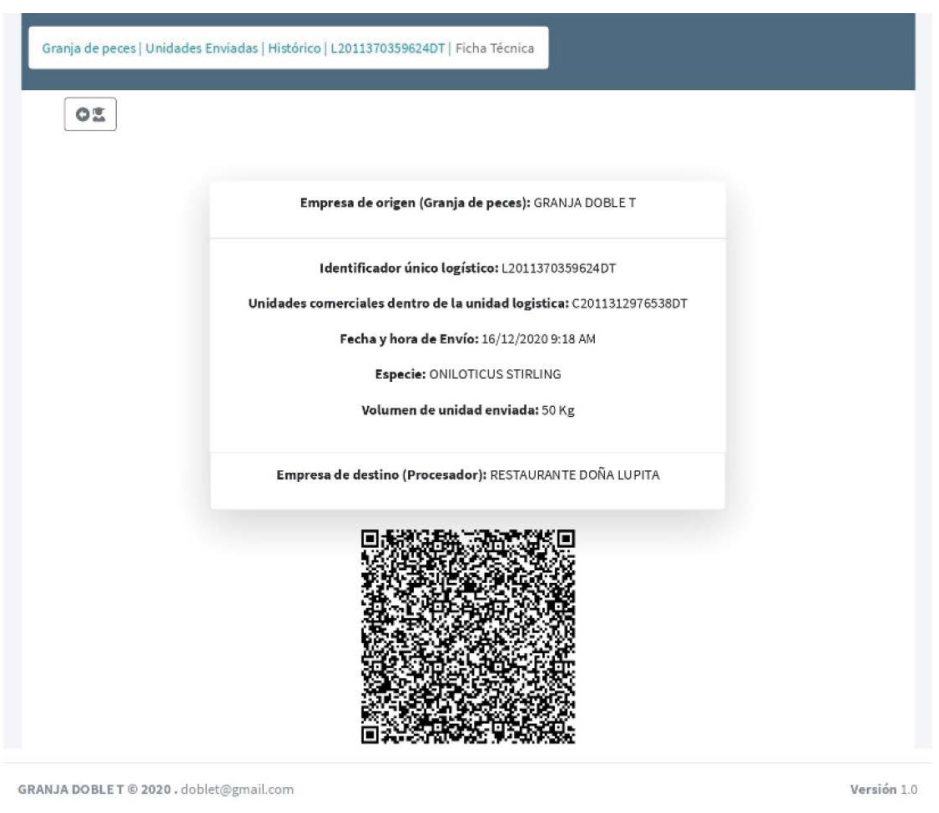

Figure 2. Technical data sheet of the unit sent.

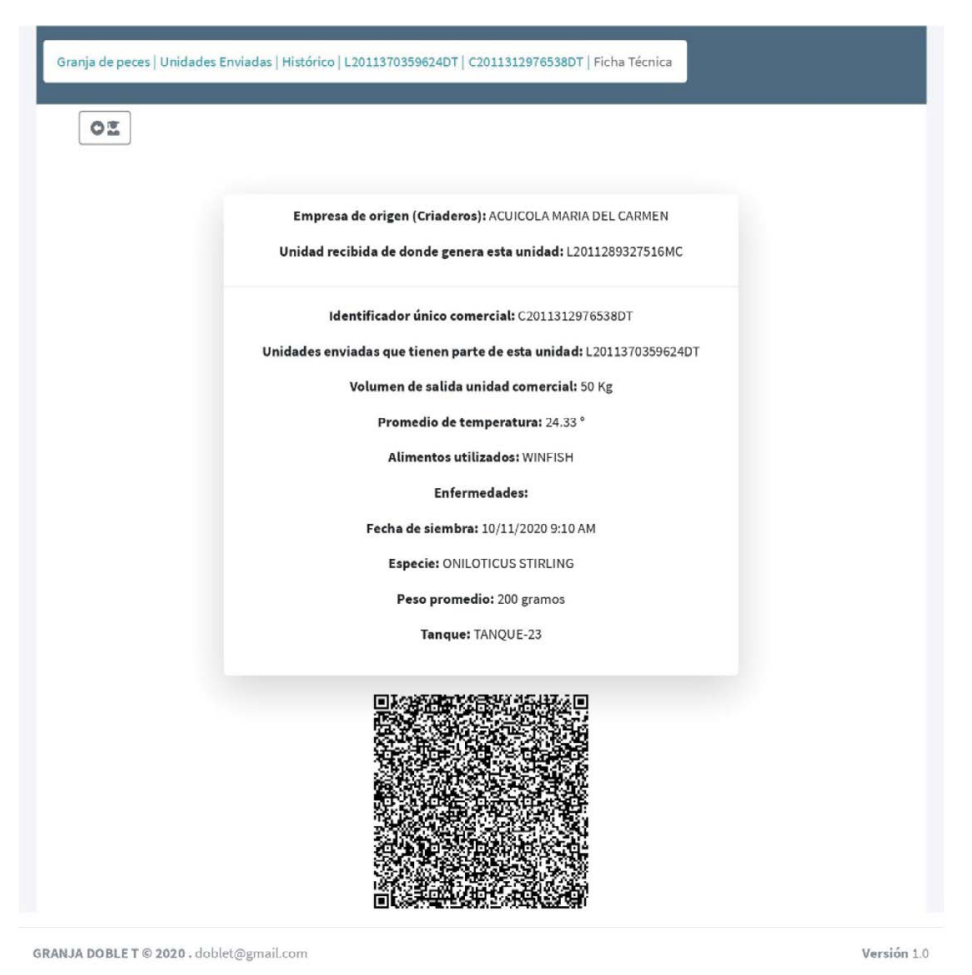

Figure 3. Commercial unit data sheet.

In Figure 3, the data described in the technical data sheet correspond to the commercial unit, including planting date, average temperature, diseases recorded, name of the food used during production, as well as the unique identifier of that commercial unit, which is constituted in accordance with the standard. The ISO 12877:2011 standard provides a generic basis for traceability, giving flexibility for companies to add lot-specific information, 
which helps them to trace the origin of the lot quickly and easily, having unique IDs with standardized format. The system allows obtaining the technical file of the unit shipped, for which the user must follow the corresponding method according to the type of food business operator performed. This is the case of the Fish Farm operator, who registers the supplier's identification data, such as name, RFC, e-mail, among others. Once registered, the unit received can be created, with its respective unique identifier; subsequently, the system allows adding the new commercial unit for the business operator, specifying the amount of fry used for that unit, as well as the corresponding percentage used of the unit received. As shown in (Figure 4), the information required by the standard such as physicochemical parameters, cleanliness, feed, diseases, and treatments corresponding to the diseases presented during the production stage in the commercial unit is enabled to be recorded.

The fish farm operators know that the species is ready for sale when it has the specific weight and size desired, generally when above $300 \mathrm{~g}$; when this happens, the employee authorized to make the sale must ensure that the business associate or customer to whom the unit will be sent is registered, otherwise the system automatically generates the unique logistic identifier as part of the shipping process; at the same time the user must indicate which commercial units will be loaded, and the approximate percentage and kilograms of tilapia; finally, the current unit is placed on hold to add additional commercial units; if this is not the case, the user can archive the dispatched unit by simply pressing a button. As part of the dispatch process, the system is responsible for creating the required records to register the commercial units that were sent in their totality, as well as the dispatched unit itself, in order to enable the traceability data sheet for each unit.

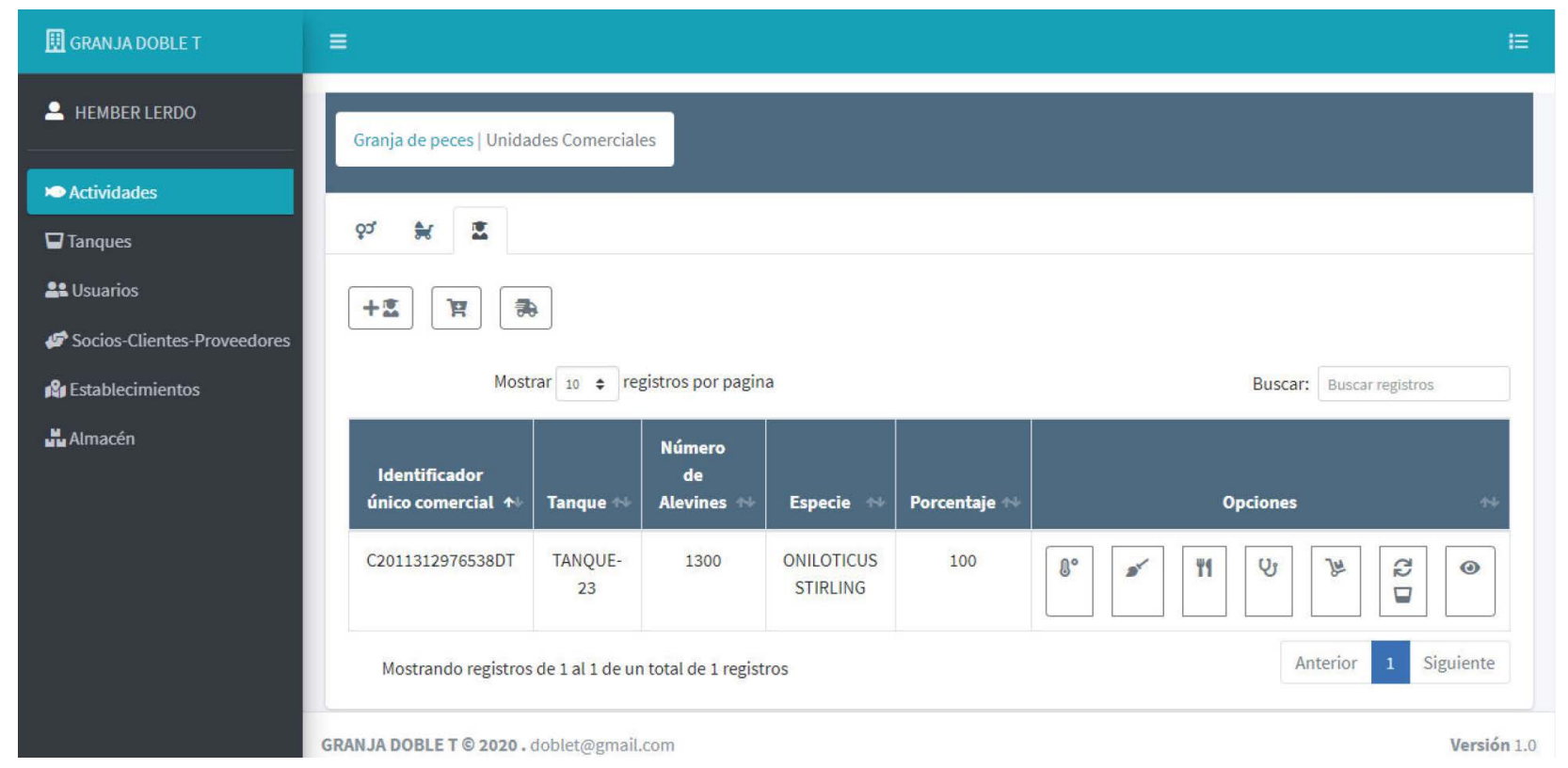

Figure 4. Commercial fish farm units. 
Table 2. Comparison of traceability systems found.

\begin{tabular}{|c|c|c|c|c|c|c|c|}
\hline Funcionality & 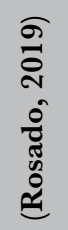 & 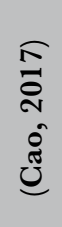 & 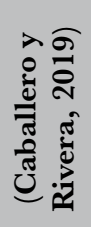 & 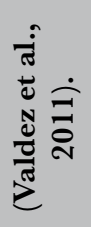 & 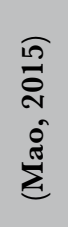 & 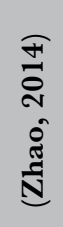 & 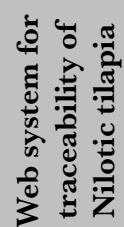 \\
\hline $\begin{array}{l}\text { Enables predictive analytics with artificial intelligence or other } \\
\text { technology. }\end{array}$ & No & Yes & Yes & No & Yes & Yes & No \\
\hline It has inventory management and accounting modules. & Yes & Yes & Yes & Yes & - & - & Yes \\
\hline Generates specific reports for each lot or product & Yes & Yes & Yes & Yes & - & Yes & Yes \\
\hline Its construction is based on a traceability standard. & No & Yes & No & No & - & - & Yes \\
\hline
\end{tabular}

No information on the functionality evaluated is specified.

To conclude, in Table 2 the functionalities of the proposed system are compared by way of discussion with respect to the systems presented in the literature review.

However, it was observed that the design of the systems analyzed in the literature review depends mainly on the technological needs required and not on following a standard, which is considered a disadvantage. The web system for the traceability of tilapia production and marketing in aquaculture farms stands out because it is based on an international standard, requiring the producer to keep records in accordance with the standard.

\section{GONGLUSIONS}

The web system for traceability of farmed tilapia presented, whose added value is through the articulation with ISO 12877:2011, has been implemented for usage at Doble $\mathrm{T}$ and Acuícola María del Carmen farms to align their farming processes with international traceability standards. Unlike the information record stored in notebooks, with this system the availability of data is permanent. The data is organized, centralized and its processing allows the traceability of a production batch to be evidenced by means of technical data sheets compressed in $\mathrm{QR}$ codes with the most relevant data of a produced batch or of a shipped batch, which is considered essential because several produced batches can be broken down, being the produced batch the basic unit during the production stage. The traceability of the cultivation processes implemented by the system provides producers with the required information to cover the indicators of a possible certification of their processes and increase the reliability of their customers. As future work, the processes marked in the standard for processors, transporters and warehousers, traders and wholesalers, retailers and catering companies will be incorporated into the information system. In addition, an evaluation of the impact of the implementation of the system after its release will be carried out to identify possible areas for improvement and scalability. 


\section{ACKNOWLEDGMENTS}

To the farms 'DobleT y Acuícola María del Carmen' for the availability for the development of the web system, applicable to their tilapia farming processes; to CONACyT and the TECNM campus Instituto Tecnológico de Colima. Also, to the academic organization ITCOL-CA-7 'Emerging Technologies' for their advice and support in this paper.

\section{REFERENGES}

Caballero, R. y Rivera, B., (2019). Blockchain: An Alternative to Enable Traceability in the Agricultural Supply Chain in Panama, 7th International Engineering, Sciences and Technology Conference (IESTEC), Panama, Panama, 2019, pp. 46-51, Doi: 10.1109/IESTEC46403.2019.00017.

Callejas, L.F., Álvarez, K.C. (2020). Trazabilidad en la cadena de suministro alimentaria: Un estudio bibliométrico. Revista CIES.11. (2). 277-297.

Cao, Y., Liu, X., Guan, C., Mao, B. (2017). Implementation and Current Status of Food Traceability System in Jiangsu China, Procedia Computer Science, 122, 617-621. Doi: 10.1016/j.procs.2017.11.414.

Chávez-Almazán, L. A., Díaz-Ortiz, J. A., Garibo-Ruiz, D., Alarcón-Romero, M. A., Mata-Diaz, M. A., PérezCruz, B., Godoy-Galeana, E. (2019). Impact of health monitoring of clenbuterol in Guerrero, Mexico: Results from 2011 to 2015. Revista Mexicana de Ciencias Pecuarias, 10, (1). Doi: 10.22319/rmcp.v10i1.4350

CONAPESCA. Comisión Nacional de Acuacultura y Pesca. (2017). Anuario Estadístico de Acuacultura y Pesca 2017.Sinaloa, México.

CONAPESCA. Comisión Nacional de Acuacultura y Pesca. (2010). Anuario Estadístico de Acuacultura y Pesca 2010.Sinaloa, México.

CONAPESCA. Comisión Nacional de Acuacultura y Pesca. (2018). Anuario Estadístico de Acuacultura y Pesca 2018. Sinaloa, México.

FAO. Organización de las Naciones Unidas para la Alimentación y la Agricultura. (2017). Estadísticas de pesca y acuicultura 2017, 30. Roma, Italia.

Herrera, L., Pérez, F., Martínez, M., Hernandéz, O. (2013). Modelo dinámico para la evaluación económica de la trazabilidad en el mercado mexicano de carne de bovino. Tropical and Subtropical Agroecosystems, 16, (3). 465-473.

Huerta, M., Sandoval, S., (2018). Sistemas de calidad como estrategia de ventaja competitiva en la agroindustria alimentaria. Agricultura, Sociedad y Desarrollo.15, (1). 19-28. Doi: 10.22231/asyd.v15i1.746

ISO. Organización Internacional de Normalización. 2011. ISO 12877:2011 Traceability of finfish products Specification on the information to be recorded in farmed finfish distribution chains. Switzerland.

Mao, B., He, J., Cao, J., Stephen W. Bigger, Todor Vasiljevic, A. (2015). Framework for Food Traceability Information Extraction Based on a Video Surveillance System, Procedia Computer Science, 55. 12851292, Doi: /10.1016/j.procs.2015.07.139

Nikolaus, W. P., (2020). How emerging data technologies can increase trust and transparency in fisheries, ICES Journal of Marine Science,77, (4).1286-1294 Doi: 10.1093/icesjms/fsz036

Peña, G.A., Sanchez, J., Aguirre, H., García T. (2016). "Thermal Feasibility of Tilapia Production under Greenhouse Conditions in a Semi-Desert Region of Mexico". IEEE Xplore. DOI: 10.1109/ CONIIN.2016.7498116

Rosado da Cruz, A. M. et al., "On the Design of a Platform for Traceability in the Fishery and Aquaculture Value Chain," 2019 14th Iberian Conference on Information Systems and Technologies (CISTI), Coimbra, Portugal, 2019, pp. 1-6, Doi: 10.23919/CISTI.2019.8760891.

Valdez, G., Torrescano, G., Sánchez, A., Paz, R. , Vázquez, M., Pardo, D. (2011). Acortando la brecha digital para la trazabilidad sanitaria: el problema de la transferencia tecnológica en la ganadería sonorense, caso SITAGAN. Estud. soc. 19, (37), 141-174..

Yu, B., Zhan, P., Lei, M., Zhou, F., Wang, P., "Food Quality Monitoring System Based on Smart Contracts and Evaluation Models," in IEEE Access, vol. 8, pp. 12479-12490, 2020, doi: 10.1109/ ACCESS.2020.2966020.

Zhao G., Yu H., Wang G., Sui Y., Zhang L. (2015) Applied Research of IOT and RFID Technology in Agricultural Product Traceability System. In: Li D., Chen Y. (eds) Computer and Computing Technologies in Agriculture VIII. CCTA 2014. IFIP Advances in Information and Communication Technology, vol 452. Springer, Cham. Doi: 10.1007/978-3-319-19620-6_57 .

Šenk I., Ostojić G., Tarjan L., Stankovski S., Lazarević M. (2013) Food Product Traceability by Using Automated Identification Technologies. Springer, Berlin. 